\title{
Evaluation of Efficacy and Safety of Upfront Weekly Nanoparticle Albumin-bound Paclitaxel for HER2-negative Breast Cancer
}

\author{
AKIRA MATSUI ${ }^{1}$, AKIHIKO TATIBANA ${ }^{2}$, NORIYUKI SUZUKI $^{3}$, MASARU HIRATA $^{4}$, YOKO OISHI $^{5}$, \\ YOUHEI HAMAGUCHI $^{6}$, YUYA MURATA ${ }^{7}$, AIKO NAGAYAMA $^{1}$, YUKO IWATA $^{1}$ and YASUSHI OKAMOTO ${ }^{8}$ \\ Departments of ${ }^{1}$ Breast Surgery, and ${ }^{7}$ Pathology, \\ National Hospital Organization, Tokyo Medical Center, Tokyo, Japan; \\ ${ }^{2}$ Department of Breast Surgery, Kanto Central Hospital of the Mutual \\ Aid Association of Public School Teachers, Tokyo, Japan; \\ ${ }^{3}$ Department of Breast Surgery, Omori Red Cross Hospital, Tokyo, Japan; \\ ${ }^{4}$ Department of Breast Surgery, JR Tokyo General Hospital, Tokyo, Japan; \\ ${ }^{5}$ Department of Breast Surgery, Nissan Tamagawa Hospital, Tokyo, Japan; \\ ${ }^{6}$ Department of Breast Surgery, Futakotamagawa Breast Clinic, Tokyo, Japan; \\ ${ }^{8}$ Department of Breast Surgery, Toho University Medical Center Ohashi Hospital, Tokyo, Japan
}

\begin{abstract}
Background: Taxanes are among the key drugs for breast cancer treatment. This study aimed to evaluate the efficacy of upfront weekly nanoparticle albumin-bound paclitaxel (Nab-PTX; $100 \mathrm{mg} / \mathrm{m}^{2}$ ) for human epidermal growth factor 2 (HER2)-negative breast cancer. Patients and Methods: Patients with stage II to IV breast cancer received 12 cycles of weekly $100 \mathrm{mg} / \mathrm{m}^{2} \mathrm{Nab}-\mathrm{PTX}$ as first-line treatment. Preoperative chemotherapy with anthracyclines after Nab-PTX was recommended. Results: From 2012 to 2014, we enrolled 66 patients. The overall response rate after Nab-PTX was $59.1 \%$ [95\% confidence interval $(C I)=47.2 \%$ to $71.0 \%), 63.6 \%$ in those with hormone receptor-positive tumors, and $36.4 \%$ in those with triple-negative tumors. The pathological complete response rate at surgery was $15 \%$ (95\% CI=6.1\% to $24.4 \%$ ). Toxicity analysis showed grade 2 peripheral neuropathy in 38 patients (57.6\%), grade $2 / 3$ leukocytopenia in 29 (43.9\%) and grade 2/3 liver dysfunction in five (7.5\%). Conclusion: Weekly neoadjuvant $\mathrm{Nab}-\mathrm{PTX}$ at $100 \mathrm{mg} / \mathrm{m}^{2}$ led to good response rates (59.1\%) and was well tolerated.
\end{abstract}

Correspondence to: Dr. Akira Matsui, Department of Breast Surgery, National Hospital Organization Tokyo Medical Center, 25-1 Higashigaoka, Meguro, Tokyo 152-8902, Japan. E-mail: matsuiakira@kankakuki.go.jp

Key Words: Nanoparticle albumin-bound paclitaxel, upfront chemotherapy, response rate, pathological complete response, breast cancer, HER2-negative.
The incidence of breast cancer in females in Japan is advancing every year, with an approximate twofold increase in number over the past decade; the breast cancer mortality rate is also on the rise. Breast cancer forms clinically undetectable systemic micrometastases in the early stage, and local treatment options such as surgery or radiotherapy are insufficient for control of the cancer. From the 1970s, systemic therapy such as adjuvant chemotherapy or endocrine therapy has been clinically implemented and the result has been improvement in prognosis.

Preoperative chemotherapy for breast carcinoma in clinical practice has been carried out actively since the late 1980s, and its usefulness has been reported. The first large-scale study of preoperative chemotherapy of breast cancer was the National Surgical Adjuvant Breast and Bowel Project (NSABP) B-18 (1). Preoperative doxorubicin/ cyclophosphamide (AC) therapy and postoperative AC therapy were compared in NSABP B-18; no difference was found in disease-free (DFS) nor overall (OS) survival (2). However, these AC therapy regimens were thought to contribute to improvement in the quality of life of the patients considering the cosmetic outcomes by increasing the breast preservation rate after preoperative chemotherapy and relieving the trauma associated with breast loss (3). In addition to treatment benefits, neoadjuvant chemotherapy facilitates the evaluation of predictive biomarkers.

Sequential anthracycline and taxane-based therapies are widely adopted as the main regimens in preoperative chemotherapy (4-6). Solvent-based taxanes, docetaxel and paclitaxel, are well-established treatment strategies for breast cancer (4). 
The pharmaceutical preparation of paclitaxel requires a surfactant (Kolliphor-EL) and alcohol because of the poor solubility in water $(7,8)$. The surfactant is thought to cause anaphylactic reaction and tardive neuropathy. Nab-paclitaxel (Nab-PTX; Celgene Corporation, Summit, NJ, USA), a solvent-free, albumin-bound form of paclitaxel, was designed to improve the therapeutic effect of paclitaxel. As Nab-PTX does not contain this surfactant and alcohol, administration of a steroid or antihistamine is not needed as pre-medication.

The CA024 study revealed that weekly Nab-PTX was associated with a significantly higher response rate than docetaxel in patients with metastatic breast cancer (9); similarly, weekly Nab-PTX as preoperative chemotherapy can be expected to have a favorable therapeutic effect. Therefore, to elucidate the clinical utility of weekly NabPTX monotherapy, we conducted an upfront treatment study using weekly Nab-PTX $\left(100 \mathrm{mg} / \mathrm{m}^{2}\right)$ in patients with clinical stage II/III and IV human epidermal growth factor 2 (HER2) negative breast cancer.

We expected a higher response rate and good tolerability by replacing docetaxel with weekly Nab-PTX in the therapy regimen of docetaxel followed by 5-fluorouracil/ epirubicin/cyclophosphamide (FEC). The dose of weekly Nab-PTX was adopted as $100 \mathrm{mg} / \mathrm{m}^{2}$ based on adverse effects and efficacy.

\section{Patients and Methods}

Study design. This open-label, multicenter phase II study was designed to evaluate the efficacy and safety of upfront Nab-PTX treatment for stage II-III and IV disease. The primary objective was to determine the overall response rate (ORR). Secondary objectives were to evaluate pathological complete response (pathological CR) rate and safety profile of Nab-PTX.

The study was performed in accordance with the Declaration of Helsinki, and the study protocol was approved by the Institutional Review Board of the Toho University School of Medicine and by local Ethics Committees of each participating institution. Written informed consent was obtained from all patients before screening assessments or enrollments. The trial was registered at University Hospital Medical Information Network Clinical Trial Registry (UMIN-CTR) with ID number UMIN000009526.

Patient eligibility criteria. Women who met the following criteria were eligible for inclusion: histologically confirmed primary breast carcinoma with at least one measurable lesion according to the Response Evaluation Criteria in Solid Tumors (RECIST) version 1.1 (10); women aged 20-80 years with histologically proven HER2negative breast cancer; Eastern Cooperative Oncology Group performance status (ECOG PS) score of 0,1 or 2; no prior chemotherapy, endocrine therapy, radiotherapy, immunotherapy, or surgery for breast cancer; normal electrocardiogram; cut-off values for laboratory values were as follows: neutrophil count $\geq 1.5 \times 10^{9} / 1$, platelet count $\geq 100 \times 10^{9} / 1$, hemoglobin level $\geq 9.0 \mathrm{~g} / \mathrm{dl}$; serum bilirubin level $<2.0 \times$ upper limit of normal level; aspartate aminotransferase (AST), alanine aminotransferase (ALT), and alkaline phosphatase levels $<2.5 \times$ upper limit of normal level; and serum creatinine level $<1.5 \mathrm{mg} / \mathrm{dl}$. Patients were excluded if they had a serious concomitant illness such as uncontrolled diabetes, severe cardiovascular disease, interstitial pneumonia, lung fibrosis, or active concomitant malignancy. Pregnant or lactating women were also excluded.

Treatment. Patients with stage II to IV HER2-negative breast cancer received 12 cycles of weekly $100 \mathrm{mg} / \mathrm{m}^{2} \mathrm{Nab}-\mathrm{PTX}$ as first-line treatment. Treatment was continued in the absence of unacceptable toxicity or disease progression during the course of chemotherapy. The subsequent treatment after this protocol was not specified. However, preoperative chemotherapy with anthracycline-containing regimens after Nab-PTX was permitted. After neadjuvant chemotherapy, most patients underwent either mastectomy or partial mastectomy, with either axillary lymph node dissection or sentinel lymph node biopsy.

Throughout the treatment regimen with Nab-PTX, the presence of toxicities was evaluated according to the National Cancer Institute Common Terminology Criteria for Adverse Events (CTCAE version 4) (11). Treatment was to be postponed for a maximum of 2 weeks in the case of severe toxicity. Dose reductions of Nab-PTX from $100 \mathrm{mg} / \mathrm{m}^{2}$ to $80 \mathrm{mg} / \mathrm{m}^{2}$ were permitted in cases of febrile neutropenia and grade 3 or 4 non-hematological toxicities.

Evaluation of response. Clinical TNM classification (Union of International Cancer Control, version 7) (12) and clinical stage (General Rules for Clinical and Pathological Recording of Breast Cancer, The Japanese Breast Cancer Society, 17th edition) (13) were evaluated and determined before preforming neadjuvant chemotherapy. The clinical tumor size and nodal status was evaluated by ultrasonography (US), computed tomography (CT), or magnetic resonance imaging (MRI). We used CT scans to detect distant metastasis. During protocol treatment, tumor size was monitored every 2 weeks by palpation and was measured by the same device (CT or MRI) at both baseline and protocol completion.

According to the criteria of RECIST 1.1, complete response (CR) was defined as disappearance of all tumor foci after chemotherapy. Partial response (PR) was defined as a decline of at least $30 \%$ in tumor maximum diameters, and progressive disease (PD) was defined as an increase of at least $20 \%$ from the baseline in the sum measure of all tumor diameters. Disease was categorized as stable disease (SD) when CR, PR, or PD was not noted. Tumor size was also measured using the same device as baseline prior to surgery.

Histological assessment of tissue specimens. Breast cancer was diagnosed by core needle or vacuum-assisted biopsy specimen prior to any treatment. Estrogen receptor (ER), progesterone receptor $(\mathrm{PgR})$, and Ki-67 status were evaluated using semiquantitative immunohistochemistry (IHC) scoring of the percentage of cells with positive nuclear staining (1-100\%). We used the following clones for IHC: mouse monoclonal antibody against ER (clone 1D5; Dako Cytomation, Carpinteria, CA, USA); mouse monoclonal antibody against PgR (clone PgR636; Dako) and mouse monoclonal antibody against Ki-67 (MIB-1; Dako). Positivity for ER and PgR was defined as nuclear staining in $>1 \%$ of tumor cells. The HER2 status was assessed using IHC or fluorescence in situ hybridization (FISH). HER2 expression was scored 0 to $3+$ by IHC, with HER2 positivity defined by an IHC score of $3+$ or HER2 gene amplification on FISH assessment. 
Pathologists also evaluated and recorded histological type and pathological response to neadjuvant chemotherapy based on the findings in the surgical specimen. Pathological CR was defined as the absence of any residual invasive cancer on evaluation of the resected breast specimen by hematoxylin and eosin staining. Residual ductal carcinoma in situ was included in the pathological CR category. All microscopy slides were independently evaluated by at least two senior pathologists.

Statistical analysis. Efficacy and safety analyses were performed on the intention-to-treat (ITT) population using SPSS statistical software (version 23.0; IBM Corp., Armonk, NY, US). Values of $p<0.05$ were considered to indicate a statistically significant difference. The primary objective of this study was to show adequate activity of Nab-PTX treatment measured by ORR. The sample size was calculated based on historical data from a randomized phase III study of a first-line therapy, which demonstrated a response rate of $45 \%$ in first-line therapy for patients with metastatic breast cancer. Therefore, achievement of a response rate of more than $45 \%$ indicated that the treatment results could be used for further development of this dose and schedule of Nab-PTX. Accrual of 42 assessable patients to this trial allowed adequate assessment of treatment toxicity and provided a response rate with $95 \%$ confidence intervals (CI) $\pm 15 \%$. However, we had recruited more patients to account for drop out from intensified therapy.

\section{Results}

Patient characteristics and clinicopathological variables. From December 2012 to December 2014, we enrolled 66 patients from six institutes in Tokyo (Figure 1). The baseline patient characteristics are summarized in Table I. The median age of patients was 57 years (range $=37-80$ years). All patients were diagnosed with invasive ductal carcinoma on core needle or vacuum-assisted biopsy. Among the 66 patients, most $(55 ; 83.3 \%)$ had hormone receptor-positive tumors (luminal type). Of the 66 patients, 57 (86.4\%) completed all 12 cycles of treatment. One patient withdrew after receiving the first cycle. Two patients discontinued Nab-PTX because of PD and six because of adverse effects. Among the 57 patients who completed the 12 cycles of NabPTX, the average treatment period was 85.2 days and almost all cases were treated without delay.

Efficacy. The maximum change in tumor size in each patient is shown in Figure 2. The ORR with Nab-PTX regimen was $59.1 \%(95 \% \mathrm{CI}=47.2-71.0 \%): 63.6 \%$ in those with luminal type tumors and $36.4 \%$ in those with triple-negative tumors (Table II). Consequently, 49 patients received FEC after Nab-PTX, 47 of whom completed the FEC regimen (96\%). Finally, 59 patients underwent operation of the breast; among them, 46 patients received the FEC regimen preoperatively. Breast-conserving surgery was performed for 25 of the 66 patients (37.9\%) (Table III). A pathological CR (ypT0/Tis ypN0. grade 3), which was the secondary end-point of this

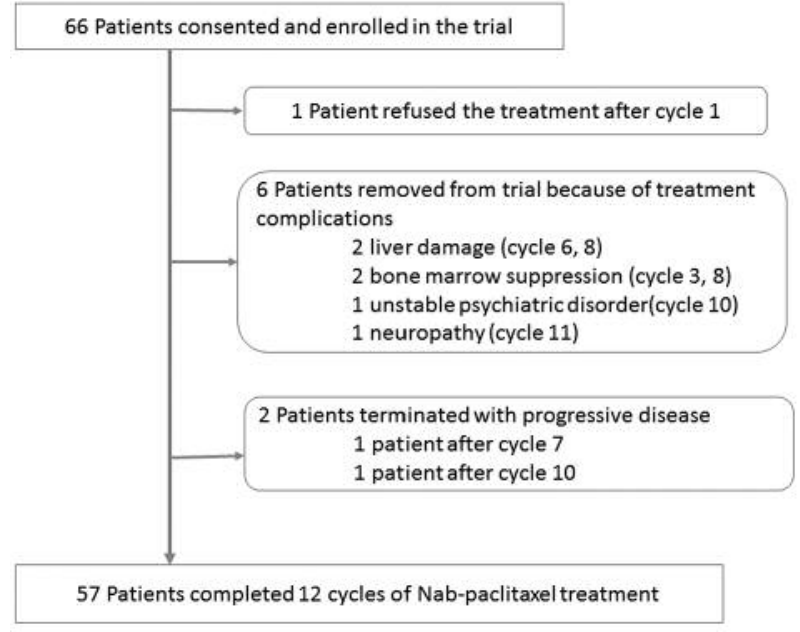

Figure 1. Consort diagram for the study.

study, was observed in nine out of the 59 patients $(15 \%$; 95\% $\mathrm{CI}=6.1-24.4 \%$ ). The pathological $\mathrm{CR}$ rate for patients with the luminal and triple-negative subtypes was $14.0 \%$ (7/50) and 22.2\% (2/9), respectively (Table IV). Among seven patients who did not undergo operation of the breast, five had stage IV progressive disease, one had wellcontrolled stage III disease, and one was lost to follow-up because of a worsening psychiatric disorder.

Safety. Toxicity analysis showed grade 2 peripheral sensory neuropathy in 38 patients $(57.6 \%)$, grade 2 or grade 3 leukocytopenia in $29(43.9 \%)$, grade 2 or grade 3 neutropenia in $20(30.4 \%)$, and grade 2 or grade 3 liver dysfunction in $5(7.5 \%)$ (Table V).

Treatment for neutropenia, detected as an adverse effect, demanded a dose reduction in one patient (1.5\%). Six patients $(9.3 \%)$ discontinued Nab-PTX treatment before the completion of 12 cycles due to serious adverse effects: liver damage in two patients, bone marrow suppression in two, neuropathy in one, and unstable psychiatric disorder in one.

\section{Discussion}

In this clinical trial, we evaluated the response rate of upfront weekly Nab-PTX therapy for HER2-negative primary breast cancer, and the efficacy result was $59.1 \%$ by ITT analysis.

Although Nab-PTX has been widely used for metastatic breast cancer $(7,14,15)$, there are only a few reports on the therapeutic efficacy and safety profile of Nab-PTX monotherapy in an upfront setting (16-18). Moreover, most studies of neoadjuvant Nab-PTX in breast cancer reported 
Table I. Patient characteristics.

\begin{tabular}{|c|c|}
\hline Characteristic & Value \\
\hline \multicolumn{2}{|l|}{ Gender } \\
\hline Male:female & $0: 66$ \\
\hline Median age (range), years & $57(37-80)$ \\
\hline \multicolumn{2}{|l|}{ Menopausal status } \\
\hline Premenopausal & $22(33.3)$ \\
\hline Postmenopausal & $44(66.7)$ \\
\hline \multicolumn{2}{|l|}{ ECOG PS, n (\%) } \\
\hline 0 & $63(95.5)$ \\
\hline 1 & $3(4.5)$ \\
\hline \multicolumn{2}{|l|}{ Clinical tumor stage, $\mathrm{n}(\%)$} \\
\hline $\mathrm{T} 1$ & $3(4.5)$ \\
\hline $\mathrm{T} 2$ & $33(50.0)$ \\
\hline $\mathrm{T} 3$ & $10(15.2)$ \\
\hline $\mathrm{T} 4$ & $19(28.8)$ \\
\hline \multicolumn{2}{|l|}{ Clinical nodal stage, n (\%) } \\
\hline No & $12(18.2)$ \\
\hline $\mathrm{N} 1$ & $45(68.2)$ \\
\hline $\mathrm{N} 2$ & $6(9.1)$ \\
\hline N3 & $3(4.5)$ \\
\hline \multicolumn{2}{|l|}{ Clinical stage, $\mathrm{n}(\%)$} \\
\hline II & $38(57.6)$ \\
\hline III & $18(27.3)$ \\
\hline IV & $10(15.1)$ \\
\hline \multicolumn{2}{|l|}{ ER status, n (\%) } \\
\hline Positive & $55(83.3)$ \\
\hline Negative & $11(16.7)$ \\
\hline \multicolumn{2}{|l|}{ PgR status, n (\%) } \\
\hline Positive & $40(60.6)$ \\
\hline Negative & $26(39.4)$ \\
\hline \multicolumn{2}{|l|}{ HER2 status, n (\%) } \\
\hline 0 & $19(28.8)$ \\
\hline 1 & $40(60.6)$ \\
\hline 2 & $7(10.6)$ \\
\hline \multicolumn{2}{|l|}{ Subtype, n (\%) } \\
\hline Luminal type & $55(83.3)$ \\
\hline Triple-negative type & $11(16.7)$ \\
\hline \multicolumn{2}{|l|}{ Nuclear grade, n $(\%)$} \\
\hline 1 & $15(22.7)$ \\
\hline 2 & $21(31.8)$ \\
\hline 3 & $30(45.5)$ \\
\hline
\end{tabular}

ECOG PS: Eastern Cooperative Oncology Group performance states score; ER: estrogen receptor; HER2: human epidermal growth factor receptor 2; PgR: progesterone receptor.

on the every-3-week $(q 3 w)$ Nab-PTX administration regimen $(16,17,19-21)$. A significantly improved ORR (33 $v s .19 \% ; p=0.001)$ and time to tumor progression $(23.0 \mathrm{vs}$. 16.9 weeks; hazard ratio $=0.75 ; p=0.006$ ) were reported with $260 \mathrm{mg} / \mathrm{m}^{2} \mathrm{Nab}-\mathrm{PTX} q 3 w$ vs. $175 \mathrm{mg} / \mathrm{m}^{2}$ paclitaxel $q 3 w$ in a phase III clinical trial for metastatic breast cancer (7). Weekly solvent-based paclitaxel therapy resulted in superior efficacy compared with $\mathrm{q} 3 \mathrm{w}$ treatment in patients with metastatic breast cancer (ORR $=42 \%$ vs. 29\%,
Table II. Response rate by breast cancer subtype for the intention-totreat population.

\begin{tabular}{lccc}
\hline & $\begin{array}{c}\text { Luminal } \\
\text { type }(\mathrm{N}=55)\end{array}$ & $\begin{array}{c}\text { Triple-negative } \\
\text { type (N=11) }\end{array}$ & Total \\
\hline Overall response, $\mathrm{n} \mathrm{( \% )}$ & $35(63.6)$ & $4(36.4)$ & $39(59.1)$ \\
Complete response & 0 & 0 & 0 \\
Partial response & $35(63.6)$ & $4(36.4)$ & $39(59.1)$ \\
Stable disease & $16(29.1)$ & $3(27.3)$ & $19(28.8)$ \\
Progressive disease & $2(3.6)$ & $1(9.1)$ & $3(4.5)$ \\
Not evaluable & $2(3.6)$ & $3(27.3)$ & $5(7.6)$ \\
\hline
\end{tabular}

Table III. Breast surgery after neo-adjuvant treatment.

\begin{tabular}{lc}
\hline Result & Number of patients $(\%)$ \\
\hline Preoperative treatment & \\
Nab-PTX only & $13(19.7)$ \\
Nab-PTX plus FEC & $46(69.7)$ \\
Breast & \\
Breast-conserving surgery & $25(37.9)$ \\
Total mastectomy & $34(51.5)$ \\
No surgery & $7(10.6)$ \\
Pathological nodal involvement & \\
n0 & $25(37.9)$ \\
n1-3 & $25(37.9)$ \\
n4-9 & $9(13.6)$ \\
n10- & $3(4.5)$ \\
Unknown & $7(10.6)$ \\
\hline
\end{tabular}

FEC: 5-Fluorouracil/epirubicin/cyclophosphamide; Nab-PTX: nanoparticle albumin-bound paclitaxel.

Table IV. Pathological response rate by breast cancer subtype for patients who underwent surgery

\begin{tabular}{lccc}
\hline $\begin{array}{l}\text { Pathological } \\
\text { response }\end{array}$ & $\begin{array}{c}\text { Luminal type } \\
(\mathrm{N}=50), \mathrm{n}(\%)\end{array}$ & $\begin{array}{c}\text { Triple-negative } \\
\text { type }(\mathrm{N}=9), \mathrm{n}(\%)\end{array}$ & $\begin{array}{c}\text { Total }(\mathrm{N}=59), \\
\mathrm{n}(\%)\end{array}$ \\
\hline Grade 0-2 & $43(86.0)$ & $7(77.8)$ & $50(84.7)$ \\
Grade 3 & $7(14.0)$ & $2(22.2)$ & $9(15.3)$ \\
\hline
\end{tabular}

$p=0.0004$; time to progression: $9 v s .5$ months, $p<0.0001$; and OS: 24 vs. 12 months, $p=0.0092$ ) (22). Chemotherapy agents, including taxanes, which are recommended in the metastatic (23) and adjuvant settings (24), are also considered in the neoadjuvant setting. Thus, in this upfront study, the therapy of administering weekly Nab-PTX was adopted. 


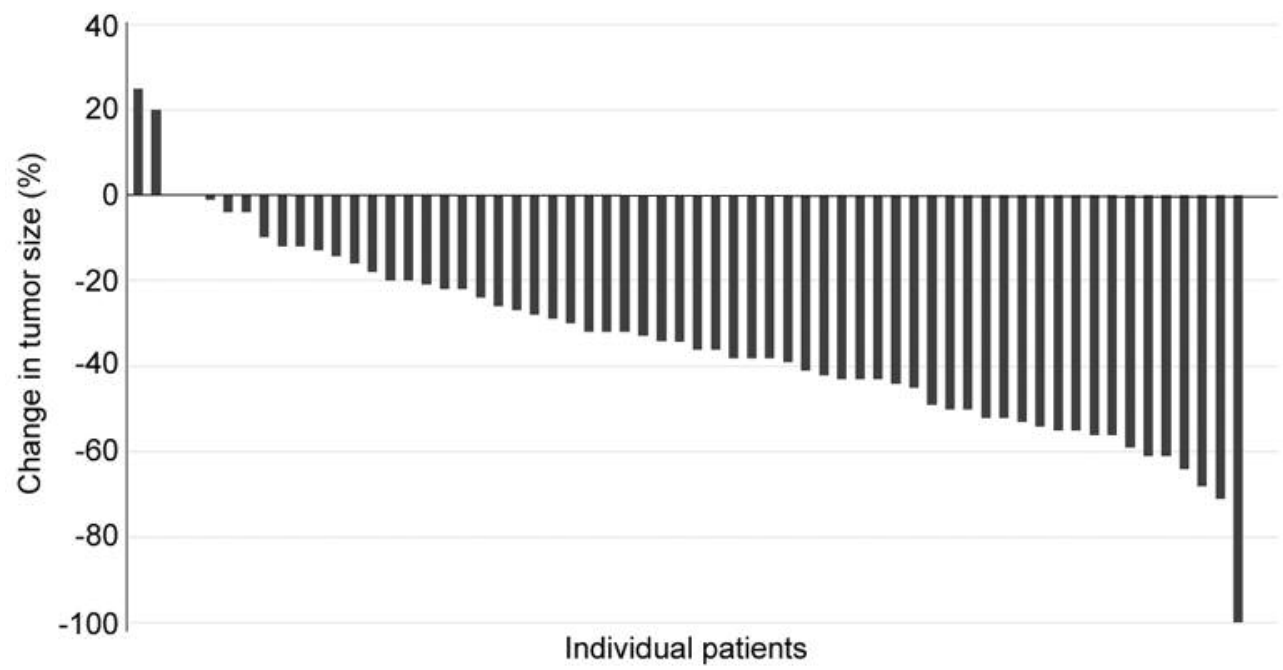

Figure 2. Waterfall plots of the percentage change in tumor size in each patient after 12 cycles of Nab-paclitaxel.

Robidoux et al. evaluated weekly $100 \mathrm{mg} / \mathrm{m}^{2} \mathrm{Nab}-\mathrm{PTX}$ followed by FEC for previously untreated breast cancer in a phase II trial $(\mathrm{N}=66)(25)$. The clinical $\mathrm{CR}$ based on investigator assessment by physical examination after NabPTX therapy was $34 \%$ (22 out of 65 ), and that after completion of FEC increased to 55\% (36 out of 65 ). The clinical $\mathrm{CR}$ rate was very high in comparison with that obtained in our study, but the response was evaluated only by physical examination. In addition, the inclusion of $29 \%$ of HER2-positive patients probably contributed to the good result. Using a resected specimen, the pathological $\mathrm{CR}$ rate of patients with triple-negative tumors was determined to be $28 \%$ ( 5 out of 18 ) and the pathological CR rate of patients with luminal tumors was $11 \%$ (3 out of 28). The final pathological CR rate was equivalent to that in our study.

The phase III GeparSepto trial compared neoadjuvant weekly $80 \mathrm{mg} / \mathrm{m}^{2}$ paclitaxel $(\mathrm{n}=600) v s$. weekly Nab-PTX $(n=606)$ followed by epirubicin and cyclophosphamide as a neoadjuvant regimen for early-stage breast cancer (26). GeparSepto originally adopted weekly $150 \mathrm{mg} / \mathrm{m}^{2} \mathrm{Nab}-$ PTX, which caused more peripheral neuropathy and frequent discontinuations than paclitaxel. Hence, after recruitment of 464 patients, the study protocol was amended to use weekly $125 \mathrm{mg} / \mathrm{m}^{2} \mathrm{Nab}-\mathrm{PTX}$. The final pathological CR (ypT0 ypN0) for all patients was reported to be $29.0 \%$ in the paclitaxel arm and $38.4 \%$ in the Nab-PTX arm. The superior results were probably owing to the presence of $56 \%$ of patients with chemotherapy-sensitive HER2-positive and triple-negative disease, their relatively young age, and early stages of the disease. Judging from the response to
Table V. Treatment-related toxicity.

\begin{tabular}{lccc}
\hline Toxicity & Grade $1, \%$ & Grade 2,\% & Grade 3,\% \\
\hline Hematological & & & \\
$\quad$ Leukocytopenia & 16.7 & 30.3 & 13.6 \\
Neutropenia & 3.0 & 15.2 & 15.2 \\
$\quad$ Anemia & 28.8 & 16.7 & 4.5 \\
$\quad$ Thrombocytopenia & 3.0 & 0 & 0 \\
Neuropathy & 21.2 & 57.6 & \\
Nausea & 6.1 & 3.0 & \\
Anorexia & 3.0 & 6.1 & 1.5 \\
Fatigue & 1.5 & 10.6 & 1.5 \\
Diarrhea & 1.5 & 1.5 & \\
Myalgia & 1.5 & 9.1 & \\
Arthralgia & 13.6 & 10.6 & \\
Elevated transaminase & 30.3 & 4.5 & 3.0 \\
Alopecia & 19.7 & 69.7 & \\
\hline
\end{tabular}

treatment, solvent-based paclitaxel can be substituted by Nab-PTX. However, in patients treated with either weekly 150 or $125 \mathrm{mg} / \mathrm{m}^{2}$ Nab-PTX, grade $3 / 4$ peripheral sensory neuropathy was significantly higher in the Nab-PTX arm compared with the paclitaxel arm $(10.4 \% v s .3 \%, p<0.0001)$ (26). Therefore, the adopted dose of weekly $100 \mathrm{mg} / \mathrm{m}^{2}$ Nab-PTX in our study should be adequately verified for efficacy and adverse effects.

A phase I dose-escalation study in patients with solid tumors determined that the maximum tolerated dose of Nab-PTX administered q3w was $300 \mathrm{mg} / \mathrm{m}^{2}$. Dose-limiting toxicities 
included sensory neuropathy, stomatitis, and superficial keratopathy (8). The adopted Nab-PTX dose of $100 \mathrm{mg} / \mathrm{m}^{2}$ weekly in this study is the same dose intensity of Nab-PTX administered q3w $300 \mathrm{mg} / \mathrm{m}^{2}$. The dose of $100 \mathrm{mg} / \mathrm{m}^{2} \mathrm{Nab}-$ PTX seems to have become the basis for the regimen administering Nab-PTX every week $(27,28)$.

Paclitaxel is formulated with Kolliphor-EL, which can cause hypersensitivity reactions and peripheral neuropathy. Binding paclitaxel to albumin nanoparticles minimizes these toxicities, avoiding the use of prophylactic antihistamine and steroid treatment. According to a previous experimental study, the intra-tumoral paclitaxel concentration derived from Nab-PTX is higher than that derived from standard paclitaxel regimens (29). In addition, Nab-PTX is transported more rapidly across endothelial cell layers, exhibits greater tissue penetration, and has slower elimination than paclitaxel. Compared with paclitaxel, NabPTX yields a 10-fold higher mean maximal concentration of free paclitaxel. In addition to the superiority of pharmacokinetics, the fact that Nab-PTX does not contain alcohol is an advantage in the treatment of breast cancer. The frequency of aldehyde dehydrogenase $2(A L D H 2)$ gene polymorphisms, which are related to alcohol intolerance, is reported to be higher in Asians than in non-Asians. In the Japanese population, $A L D H 2$ analysis detected heterozygote and homozygote mutant genotypes in $44 \%$ and $3 \%$ patients, respectively (30). Therefore, it might be beneficial replacing paclitaxel with Nab-PTX for Asian patients. Furthermore, the choice of Nab-PTX could be beneficial in patients who have known drug allergies or diabetes, or in medically compromised patients for whom high-dose steroids are contraindicated.

The side effects of Nab-PTX monotherapy were closely monitored in this study. Grade 3 anemia and grade 3 neutropenia were observed in $4.5 \%$ and $15.2 \%$ of the patients, respectively. Hematological toxicity rarely caused treatment delay or dose reduction of Nab-PTX. Non-hematological toxicities, including, neuropathy, myalgia and alopecia occurred frequently with Nab-PTX, although frequency of these adverse events at grade 3 was low and acceptable. However, the occurrence of elevated transaminase was more frequent than anticipated and appropriate management was necessary for the continuation of treatment.

The final goal of neadjuvant chemotherapy is usually assumed to be to achieve a pathological CR, a factor for good prognosis, particularly in patients with HER2-positive breast cancer and triple-negative tumors. Pathological CR was significantly correlated with DFS in the NSABP B-18 trial (hazard ratio $=0.47 ; p<0.0001$ ) or OS (hazard ratio $=0.32$; $p<0.0001)$, suggesting that pathological CR after neoadjuvant treatment may predict favorable long-term outcome (31). However, Cortazar and colleagues were unable to define a clear association between increase in the frequency of pathological $\mathrm{CR}$ and improved event-free survival or overall survival (32). Especially, among lowgrade luminal type breast cancer, the frequency of pathological $\mathrm{CR}$ is substantially low, and there is little evidence of pathological CR associated with prognosis. In our study, most of the patients had luminal-type disease $(83.3 \%)$ in advanced stages, with a high average age. Therefore, instead of pathological CR, the response rate was the primary endpoint in this study. For the patients with breast cancer in our study, it was more important that upfront chemotherapy converted large, unresectable tumors to resectable tumors than attaining pathological CR. The US Food and Drug Administration supports pathological CR as an endpoint for evaluating new neoadjuvant agents for highrisk, early-stage breast cancer. However, for patients with low-grade, hormone receptor-positive tumors evaluated in neoadjuvant breast cancer trials, the use of pathological CR as an endpoint is not recommended by the Food and Drug Administration.

Overall, Nab-PTX appears to be a promising neoadjuvant agent for breast cancer therapy with an acceptable safety profile; however, toxicities including peripheral neuropathy and elevation of transaminase should be carefully monitored. The results of our study are limited because of the small sample size and the lack of a long-term follow-up. Further trials with large sample sizes and long-term observations are necessary. It is also desirable to establish accurate predictive factors in order to avoid adverse effects.

\section{Conclusion}

Weekly Nab-PTX in the upfront setting of HER2-negative breast cancer was effective and well-tolerated, especially considering peripheral sensory neuropathy. The establishment of an effective combination of Nab-PTX and a precise predictor are necessary in the near future.

\section{Funding}

None.

\section{Conflicts of Interest}

The Authors wish to declare the following conflicts of interest: Akira Matsui received research funding from Chugai Pharmaceutical (Tokyo, Japan), Daiichi Sankyo (Tokyo, Japan), Eisai (Tokyo, Japan), Takeda Pharmaceutical, (Osaka, Japan), Taiho Pharmaceutical, (Tokyo, Japan), and Aiko Nagayama holds stock in Chugai Pharmaceutical.

\section{Acknowledgements}

The Authors thank the technicians of the Clinical Examination Department for sample preparation. 


\section{References}

1 Fisher B, Brown A, Mamounas E, Wieand S, Robidoux A, Margolese RG, Cruz AB Jr., Fisher ER, Wickerham DL, Wolmark N, DeCillis A, Hoehn JL, Lees AW and Dimitrov NV: Effect of preoperative chemotherapy on local-regional disease in women with operable breast cancer: Findings from national surgical adjuvant breast and bowel project b-18. J Clin Oncol 15(7): 2483-2493, 1997.

2 Wolmark N, Wang J, Mamounas E, Bryant J and Fisher B: Preoperative chemotherapy in patients with operable breast cancer: Nine-year results from national surgical adjuvant breast and bowel project b-18. J Natl Cancer Inst Monogr 30: 96-102, 2001.

3 Rastogi P, Anderson SJ, Bear HD, Geyer CE, Kahlenberg MS, Robidoux A, Margolese RG, Hoehn JL, Vogel VG, Dakhil SR, Tamkus D, King KM, Pajon ER, Wright MJ, Robert J, Paik S, Mamounas EP and Wolmark N: Preoperative chemotherapy: Updates of national surgical adjuvant breast and bowel project protocols b-18 and b-27. J Clin Oncol 26(5): 778-785, 2008.

4 Gradishar WJ: Taxanes for the treatment of metastatic breast cancer. Breast Cancer (Auckl) 6: 159-171, 2012.

5 Shao N, Wang S, Yao C, Xu X, Zhang Y, Zhang Y and Lin Y: Sequential versus concurrent anthracyclines and taxanes as adjuvant chemotherapy of early breast cancer: A meta-analysis of phase iii randomized control trials. Breast 21(3): 389-393, 2012.

6 Toi M, Nakamura S, Kuroi K, Iwata H, Ohno S, Masuda N, Kusama M, Yamazaki K, Hisamatsu K, Sato Y, Kashiwaba M, Kaise H, Kurosumi M, Tsuda H, Akiyama F, Ohashi Y, Takatsuka Y and Japan Breast Cancer Research G: Phase ii study of preoperative sequential fec and docetaxel predicts of pathological response and disease free survival. Breast Cancer Res Treat 110(3): 531-539, 2008.

7 Gradishar WJ, Tjulandin S, Davidson N, Shaw H, Desai N, Bhar $\mathrm{P}$, Hawkins $\mathrm{M}$ and O'Shaughnessy $\mathrm{J}$ : Phase iii trial of nanoparticle albumin-bound paclitaxel compared with polyethylated castor oil-based paclitaxel in women with breast cancer. J Clin Oncol 23(31): 7794-7803, 2005.

8 Ibrahim NK, Desai N, Legha S, Soon-Shiong P, Theriault RL, Rivera E, Esmaeli B, Ring SE, Bedikian A, Hortobagyi GN and Ellerhorst JA: Phase i and pharmacokinetic study of abi-007, a cremophor-free, protein-stabilized, nanoparticle formulation of paclitaxel. Clin Cancer Res 8(5): 1038-1044, 2002.

9 Gradishar WJ, Krasnojon D, Cheporov S, Makhson AN, Manikhas GM, Clawson A, Bhar P, McGuire JR and Iglesias J: Phase ii trial of nab-paclitaxel compared with docetaxel as firstline chemotherapy in patients with metastatic breast cancer: Final analysis of overall survival. Clin Breast Cancer 12(5): 313321, 2012.

10 Eisenhauer EA, Therasse P, Bogaerts J, Schwartz LH, Sargent D, Ford R, Dancey J, Arbuck S, Gwyther S, Mooney M, Rubinstein L, Shankar L, Dodd L, Kaplan R, Lacombe D and Verweij J: New response evaluation criteria in solid tumours: Revised recist guideline (version 1.1). Eur J Cancer 45(2): 228-247, 2009.

11 Cancer Therapy Evaluation Program (CTEP). Common terminology criteria for adverse events (CTCAE) v4.0. http://ctep.cancer.gov/protocolDevelopment/electronic_applicatio ns/ctc.htm\#ctc.

12 Sobin LH, Gospodarowicz MK and Wittekind C: TNM Classification of Malignant Tumours, Seventh Edition. Blackwell Publishing Ltd, 2010.
13 The Japanese Breast Cancer Society: General Rules for Clinical and Pathological Recording of Breast Cancer. 17th edition. Kanehara \& Co. L, Tokyo, Japan, 2012.

14 Gradishar WJ, Krasnojon D, Cheporov S, Makhson AN, Manikhas GM, Clawson A and Bhar P: Significantly longer progression-free survival with nab-paclitaxel compared with docetaxel as first-line therapy for metastatic breast cancer. J Clin Oncol 27(22): 3611-3619, 2009.

15 Takashima S, Kiyoto S, Takahashi M, Hara F, Aogi K, Ohsumi S, Mukai R and Fujita Y: Clinical experience with nanoparticle albumin-bound paclitaxel, a novel taxane anticancer agent, and management of adverse events in females with breast cancer. Oncol Lett 9(4): 1822-1826, 2015.

16 Shigematsu H, Kadoya T, Masumoto N, Sasada T, Emi A, Ohara M, Kajitani K and Okada M: The efficacy and safety of preoperative chemotherapy with triweekly abraxane and cyclophosphamide followed by 5-fluorouracil, epirubicin, and cyclophosphamide therapy for resectable breast cancer: A multicenter clinical trial. Clin Breast Cancer 15(2): 110-116, 2015.

17 Shimada H, Ueda S, Saeki T, Shigekawa T, Takeuchi H, Hirokawa E, Sugitani I, Sugiyama M, Takahashi T, Matsuura K, Yamane T, Kuji I, Hasebe T and Osaki A: Neoadjuvant triweekly nanoparticle albumin-bound paclitaxel followed by epirubicin and cyclophosphamide for stage ii/iii her2-negative breast cancer: Evaluation of efficacy and safety. Jpn J Clin Oncol 45(7): 642-649, 2015.

18 Zong Y, Wu J and Shen K: Nanoparticle albumin-bound paclitaxel as neoadjuvant chemotherapy of breast cancer: A systematic review and meta-analysis. Oncotarget 8(10): 1736017372, 2017.

19 Futamura M, Nagao Y, Ishihara K, Takeuchi M, Nakada T, Kawaguchi Y, Asano M, Kumazawa I, Shiroko T, Morimitsu K, Mori R, Nawa M, Shimokawa T and Yoshida K: Preoperative neoadjuvant chemotherapy using nanoparticle albumin-bound paclitaxel followed by epirubicin and cyclophosphamide for operable breast cancer: A multicenter phase II trial. Breast Cancer 24(4): 615-623, 2017.

20 Tanaka S, Iwamoto M, Kimura K, Matsunami N, Morishima H, Yoshidome K, Nomura T, Morimoto T, Yamamoto D, Tsubota Y, Kobayashi T and Uchiyama K: Phase ii study of neoadjuvant anthracycline-based regimens combined with nanoparticle albumin-bound paclitaxel and trastuzumab for human epidermal growth factor receptor 2-positive operable breast cancer. Clin Breast Cancer 15(3): 191-196, 2015.

21 Ueno NT and Mamounas EP: Neoadjuvant nab-paclitaxel in the treatment of breast cancer. Breast Cancer Res Treat 156(3): 427440, 2016.

22 Seidman AD, Berry D, Cirrincione C, Harris L, Muss H, Marcom PK, Gipson G, Burstein H, Lake D, Shapiro CL, Ungaro P, Norton L, Winer E and Hudis C: Randomized phase iii trial of weekly compared with every-3-weeks paclitaxel for metastatic breast cancer, with trastuzumab for all her-2 overexpressors and random assignment to trastuzumab or not in her-2 nonoverexpressors: Final results of cancer and leukemia group b protocol 9840. J Clin Oncol 26(10): 1642-1649, 2008.

23 Jones SE, Erban J, Overmoyer B, Budd GT, Hutchins L, Lower E, Laufman L, Sundaram S, Urba WJ, Pritchard KI, Mennel R, Richards D, Olsen S, Meyers ML and Ravdin PM: Randomized phase iii study of docetaxel compared with paclitaxel in metastatic breast cancer. J Clin Oncol 23(24): 5542-5551, 2005. 
24 Sparano JA, Wang M, Martino S, Jones V, Perez EA, Saphner T, Wolff AC, Sledge GW Jr., Wood WC and Davidson NE: Weekly paclitaxel in the adjuvant treatment of breast cancer. $\mathrm{N}$ Engl J Med 358(16): 1663-1671, 2008.

25 Robidoux A, Buzdar AU, Quinaux E, Jacobs S, Rastogi P, Fourchotte V, Younan RJ, Pajon ER, Shalaby IA, Desai AM, Fehrenbacher L, Geyer CE Jr., Mamounas EP and Wolmark N: A phase ii neoadjuvant trial of sequential nanoparticle albuminbound paclitaxel followed by 5-fluorouracil/epirubicin/ cyclophosphamide in locally advanced breast cancer. Clin Breast Cancer 10(1): 81-86, 2010.

26 Untch M, Jackisch C, Schneeweiss A, Conrad B, Aktas B, Denkert C, Eidtmann H, Wiebringhaus H, Kummel S, Hilfrich J, Warm M, Paepke S, Just M, Hanusch C, Hackmann J, Blohmer JU, Clemens M, Darb-Esfahani S, Schmitt WD, Dan Costa S, Gerber B, Engels K, Nekljudova V, Loibl S, von Minckwitz G, German Breast G and Arbeitsgemeinschaft Gynakologische Onkologie-Breast I: Nab-paclitaxel versus solvent-based paclitaxel in neoadjuvant chemotherapy for early breast cancer (geparsepto-gbg 69): A randomised, phase 3 trial. Lancet Oncol 17(3): 345-356, 2016.

27 Ando M, Yonemori K, Katsumata N, Shimizu C, Hirata T, Yamamoto $\mathrm{H}$, Hashimoto $\mathrm{K}$, Yunokawa M, Tamura $\mathrm{K}$ and Fujiwara Y: Phase i and pharmacokinetic study of nab-paclitaxel, nanoparticle albumin-bound paclitaxel, administered weekly to japanese patients with solid tumors and metastatic breast cancer. Cancer Chemother Pharmacol 69(2): 457-465, 2012.

28 Blum JL, Savin MA, Edelman G, Pippen JE, Robert NJ, Geister BV, Kirby RL, Clawson A and O'Shaughnessy JA: Phase ii study of weekly albumin-bound paclitaxel for patients with metastatic breast cancer heavily pretreated with taxanes. Clin Breast Cancer 7(11): 850-856, 2007.
29 Desai N, Trieu V, Yao Z, Louie L, Ci S, Yang A, Tao C, De T, Beals B, Dykes D, Noker P, Yao R, Labao E, Hawkins M and Soon-Shiong P: Increased antitumor activity, intratumor paclitaxel concentrations, and endothelial cell transport of cremophor-free, albumin-bound paclitaxel, abi-007, compared with cremophorbased paclitaxel. Clin Cancer Res 12(4): 1317-1324, 2006.

30 Uomori T, Horimoto Y, Mogushi K, Matsuoka J and Saito M: Relationship between alcohol metabolism and chemotherapyinduced emetic events in breast cancer patients. Breast Cancer 24(5): 702-707, 2017.

31 von Minckwitz G, Untch M, Blohmer JU, Costa SD, Eidtmann H, Fasching PA, Gerber B, Eiermann W, Hilfrich J, Huober J, Jackisch C, Kaufmann M, Konecny GE, Denkert C, Nekljudova V, Mehta K and Loibl S: Definition and impact of pathologic complete response on prognosis after neoadjuvant chemotherapy in various intrinsic breast cancer subtypes. J Clin Oncol 30(15): 1796-1804, 2012.

32 Cortazar P, Zhang L, Untch M, Mehta K, Costantino JP, Wolmark N, Bonnefoi H, Cameron D, Gianni L, Valagussa P, Swain SM, Prowell T, Loibl S, Wickerham DL, Bogaerts J, Baselga J, Perou C, Blumenthal G, Blohmer J, Mamounas EP, Bergh J, Semiglazov V, Justice R, Eidtmann H, Paik S, Piccart M, Sridhara R, Fasching PA, Slaets L, Tang S, Gerber B, Geyer CE Jr., Pazdur R, Ditsch N, Rastogi P, Eiermann W and von Minckwitz G: Pathological complete response and long-term clinical benefit in breast cancer: The ctneobc pooled analysis. Lancet 384(9938): 164-172, 2014.

Received August 17, 2017

Revised September 8, 2017 Accepted September 14, 2017 